\title{
(t)
}

\section{AÇÕES SOCIOEDUCATIVAS E SERVIÇO SOCIAL: CARACTERÍSTICAS E TENDÊNCIAS NA PRODUÇÃO BIBLIOGRÁFICA ${ }^{1}$}

Social-educational actions and social work: characteristics and tendencies of bibliographical production

\section{Telma Cristiane Sasso de Lima ${ }^{2}$ Regina Célia Tamaso Mioto 3}

\footnotetext{
${ }^{1}$ Artigo-síntese elaborado a partir dos dados que compõem a Dissertação de Mestrado intitulada As ações sócio-educativas e o projeto ético-político do Serviço Social: tendências da produção bibliográfica, apresentada em agosto de 2006 ao Programa de Pós-Graduação em Serviço Social da Universidade Federal de Santa Catarina.

2 Professora Assistente da Faculdade de Serviço Social da Universidade Federal de Alagoas. Mestre em Serviço Social pela Universidade Federal de Santa Catarina - Brasil. E-mail: <telmasasso@gmail.com>.

3 Professora Associada do Departamento de Serviço Social da Universidade Federal de Santa Catarina/Nesspp (Núcleo de Estudos Estado, Políticas Públicas, Serviço Social). Doutora em Saúde Mental pela Universidade Estadual de Campinas. Bolsista de Produtividade em Pesquisa/CNPq. E-mail: <mioto@cse.ufsc.br>.
} 


\section{temporalis}

LIMA, T. C. S. de; MIOTO, R. C. T. AÇÕES SOCIOEDUCATIVAS

\section{RESUMO}

A pesquisa bibliográfica realizada em produções do Serviço Social no período de 1993 a 2005 permitiu caracterizar as ações socioeducativas e realizar algumas observações sobre o seu caráter operativo, ensaiando uma breve sistematização. As bases gramscianas, o empowerment e a proposta freireana são as principais tendências teóricas mapeadas. No paradigma críticodialético, a concepção do que significa educar confere um componente político à ação como fator determinante. $O$ sentido da ação muda segundo o significado conferido sobre o que é educar, porque educar, para quem e com qual finalidade. Considerase que as sistematizações sobre o fazer profissional são importantes para promover: interlocução entre os Assistentes Sociais; qualificação técnico-operativa das suas ações e um diálogo teórico plural e interdisciplinar atento às bases críticas do conhecimento.

\section{PALAVRAS-CHAVE}

Ações socioeducativas. Serviço Social. Dimensão técnico-operativa.

\section{ABSTRACT}

The bibliographical study on Social Work publications between 1993 and 2005 allowed us to characterize the socio-educational activities and make some comments about their operational features, considering their brief systematization. The Gramscian bases, empowerment, and Paulo Freire's propositions are the main theoretical trends mapped. In the critical-dialectical paradigm, the conception of what it means to educate provides socio-educational action as a determining factor with a political component. The sense of action changes according to the understanding about what it is to educate, why educate, whom to educate and to what purpose. Systematization about professional conduct is considered 


\section{tempordils}

LIMA, T. C. S. de; MIOTO, R. C. T. AÇÕES SOCIOEDUCATIVAS

important so as to promote: the interlocution between social workers; technical-operational qualification of their actions; and a plural theoretical and interdisciplinary dialogue which is aware of the critical bases of knowledge.

\section{KEYWORDS}

Socio-educational actions. Social Work. Technical-operational dimension.

\section{INTRODUÇÃO}

Para apreender a intervenção profissional, é necessário observar seu movimento dentro do processo histórico e sua contribuição para a reprodução das condições materiais e sociais da vida da classe trabalhadora (IAMAMOTO, 1999). Implica reconhecer que a intervenção na realidade é atravessada por "[...] múltiplas relações com a esfera da produção/reprodução da vida social, com as instâncias de poder e com as representações culturais - científicas e ético-políticas - que influenciaram e incidiram nas sistematizações da prática e ações profissionais, ao longo do tempo" (IAMAMOTO, 1999, p. 191).

Tomar como elemento condicionante o atual Código de Ética do Serviço Social brasileiro - que expressa um projeto ético-político remete a considerar que: a intervenção tem, nos Direitos, mediações importantes no processo de busca pela transformação social, porque eles resultam de conquistas históricas da classe trabalhadora. Tal compreensão imprime às ações profissionais o compromisso calcado na finalidade de construir um processo interventivo diferente, ao agir para transformar as formas de ser e de se relacionar dos sujeitos em sociedade. Trata-se de um fazer 


\section{temporalis}

LIMA, T. C. S. de; MIOTO, R. C. T. AÇÕES SOCIOEDUCATIVAS

profissional propositivo e crítico, por isso portador de uma capacidade teórica e política gestora de alternativas porque identifica concretamente as possibilidades abertas, em cada conjuntura, para a intervenção profissional (IAMAMOTO, 1999; NETTO, 1996; 2005).

Nesse contexto, localizam-se as ações socioeducativas que, na literatura da área, são identificadas como um marco na intervenção dos Assistentes Sociais, considerando sua importância no processo de produção/reprodução social. À medida que se inscrevem na "dimensão social” desse processo, "[...] produzem efeitos reais na vida dos sujeitos", pois veiculam determinados interesses e compromissos de classe (IAMAMOTO, 1999, p. 67).

Nessa perspectiva, trata-se da ação socioeducativa referenciada no processo de construção e consolidação de uma "[...] pedagogia emancipatória pelas classes subalternas [...]”, construída a partir de condições sócio-históricas e político-ideológicas de elaboração e desenvolvimento do projeto profissional de caráter ético-político calcado no paradigma crítico-dialético (ABREU, 2002). Nessa acepção, a transformação é reconhecida como componente essencial porque, mais que transmitir e propiciar conhecimentos, a ação socioeducativa inicia um processo de conscientização pautado na apreensão crítica da realidade. Significa tanto o fortalecimento da autonomia dos indivíduos como sujeitos quanto a sua organização e mobilização em torno de necessidades comuns no campo da esfera pública. Tal compromisso amplia a luta pela efetivação do acesso aos Direitos e à Cidadania, mas tem como horizonte último a transformação social.

Na incursão histórica, a gênese desse compromisso é creditada ao Movimento de Reconceituação. A partir de então e com o fortalecimento de novas bases teóricas para a profissão, foi se 


\section{tempordils}

LIMA, T. C. S. de; MIOTO, R. C. T. AÇÕES SOCIOEDUCATIVAS

consolidando um novo princípio educativo vinculado à denominada pedagogia emancipatória, fortemente influenciado pelas perspectivas de Paulo Freire e de Antonio Gramsci (CARVALHO, 1983).

Esse novo princípio educativo propiciou a postulação da finalidade das ações socioeducativas, bem como de todo processo interventivo do Assistente Social. Assim, inscreveu a centralidade do porquê na realização das ações profissionais e do para quem elas estão direcionadas. Nesse sentido, a finalidade torna-se elemento condicionante dos objetivos e dos procedimentos das ações profissionais que devem ser construídos para contemplá-la. Portanto, é fundamental mapear e compreender as influências das tendências teóricas presentes no debate das mediações necessárias à operacionalização da ação sócio-educativa de modo a adensar reflexões acerca da dimensão técnico-operativa da profissão.

O presente artigo apresenta e debate os resultados obtidos com a pesquisa bibliográfica ${ }^{4}$ realizada com produções na área de Serviço

4 A pesquisa teve como objeto as produções de autores com formação em Serviço Social (nacionais e latino-americanos) referentes ao período de 1993 a 2005 com foco na intervenção profissional. A abrangência cronológica ocorreu devido à incipiente produção bibliográfica sobre o tema, sendo que o ano de 1993 é considerado emblemático no cenário brasileiro devido à aprovação do Código de Ética do Serviço Social. O desenho metodológico foi construído através de movimento circular/aproximações sucessivas com o referencial teórico e com o material pesquisado, através das seguintes etapas: 1) delimitação das fontes de pesquisa: livros e coletânea de textos (Cadernos de Capacitação em Serviço Social e Política Social; Coletâneas em Serviço Social Textos \& Contextos); teses e dissertações brasileiras e periódicos nacionais e internacionais (Revista Serviço Social e Sociedade; Revista Katálysis, Revista Ser Social; Revista Fronteras; Boletín Electrónico Surá; Serviço Social em Revista etc.); 2) construção e teste do instrumento de coleta de dados: roteiro de leitura; 3) coleta de dados: percurso de levantamento das informações; 4) organização dos dados coletados e exposição dos resultados: análise explicativa das soluções; 5) 


\section{temporalis}

LIMA, T. C. S. de; MIOTO, R. C. T. AÇÕES SOCIOEDUCATIVAS

Social, cujos objetivos consistiram em: caracterizar as ações socioeducativas e as formas de sua operacionalização; identificar as principais tendências no debate dos autores; e explicitar sua articulação com o projeto ético-político, ou seja, explicitar o processo de intervenção de base crítico-dialética/marxista.

A premissa da pesquisa residiu na ideia de que se articulam, no paradigma crítico-dialético, diferentes tendências teóricas sobre as formas de operacionalizar as ações socioeducativas realizadas pelos Assistentes Sociais no âmbito do atual projeto ético-político brasileiro.

As seções que compõem este artigo tratam inicialmente das tendências teóricas identificadas pela pesquisa para, em seguida, apresentar o ensaio de uma caracterização sobre a operacionalização das ações socioeducativas a partir de diferentes processos interventivos. Por fim são tecidas algumas considerações sobre essas ações no debate sobre a dimensão técnico-operativa do Serviço social.

\section{SERVIÇO SOCIAL E AÇÕES SOCIOEDUCATIVAS: TENDÊNCIAS TEÓRICAS}

A ênfase conferida às ações socioeducativas dos Assistentes Sociais está vinculada ao fato de ser uma ação com potencial para o fortalecimento de processos emancipatórios. Com ela espera-se contribuir para a formação de uma consciência crítica entre sujeitos, através da apreensão e vivência da realidade, para a

reflexão crítica e caracterização das ações socioeducativas: síntese integradora das informações. As bases teóricas que orientaram o delineamento metodológico da pesquisa bibliográfica podem ser encontradas em: a) MercadoMartìnez (2004, p. 137-174); b) Lima; Mioto (2007, p. 37-45). 


\section{tempordils}

LIMA, T. C. S. de; MIOTO, R. C. T. AÇÕES SOCIOEDUCATIVAS

construção de processos democráticos, enquanto espaços de garantia de Direitos, mediante a experiência de relações horizontais entre profissionais e usuários. Nesse processo educativo, projeta-se a emancipação e a transformação social.

Tal ênfase é importante porque a educação, em sentido amplo, é reconhecida como transmissão cultural. Para Spina e Ferreira (2004, p. 7), isso significa “[...] reconocerla como una dimensión del cotidiano de las personas y los grupos, la cual se sustancia en la interacción humana”. Nessa acepção, a educação é pensada como "[...] una práctica social, política e históricamente condicionada". Admitir a educação como socialmente condicionada supõe "[...] concebir que se materializa en la interacción social toda vez que se reproducen y recrean 0 se cuestionan y transforman conocimientos y las significaciones que sustentan a las prácticas sociales" (SPINA; FERREIRA, 2004, p. 7).

Portanto, quando determinada ação socioeducativa "[...] se hace consciente, se 'racionaliza', se materializa en un plano discursivo (aún científico), se ofrece y se demanda" (SPINA; FERREIRA, 2004, p. 8), significa que ela constitui ou é reconhecida como parte de práticas socialmente provadas e aprovadas pela totalidade, ou por algum segmento da sociedade. Consequentemente, pensar o conteúdo político da educação implica considerar a relação entre poder e saber. Essa díade está no centro de todas as "[... ] relaciones pedagógicas [...]”, pois “[...] de acuerdo a como y quiénes logren influir en la constitución de esos principios prácticos, es que se atribuirá valor social a determinados conocimientos en detrimento de otros" (SPINA; FERREIRA, 2004, p.10).

Aliada a essa concepção de educação está a constatação de que, através das ações socioeducativas, o Serviço Social participa da reprodução da dimensão social/espiritual da vida, à medida que o 


\section{temporalis}

LIMA, T. C. S. de; MIOTO, R. C. T. AÇÕES SOCIOEDUCATIVAS

processo de intervenção dos Assistentes Sociais não pode ser pensado fora dos interesses de classes antagônicas (IAMAMOTO, 1999; YASBEK, 2000). Segundo Yasbek (1999, p. 90), “[...] o Serviço Social participa tanto do processo de reprodução dos interesses de preservação do capital, quanto das respostas às necessidades de sobrevivência dos que vivem do trabalho". Nesse sentido, o caráter político-ideológico/educativo da ação profissional adquire importância, uma vez que incide na reprodução da vida dos sujeitos, buscando transformar e/ou manter seus modos de pensar e de agir. Pires (2003, p. 107) acrescenta que a condição do Serviço Social como profissão que possui "[...] natureza educativa [...]" está consubstanciada pela sua "[...] inserção na divisão sóciotécnica do trabalho na posição predominante de difusão e de reprodução de ideologia [...]”, ou seja, há uma natureza educativa no Serviço Social porque "[...] a forma como se situa no movimento social lhe outorga a tarefa de formar/educar o consenso".

Diante disso, é possível afirmar que as ações profissionais são reveladoras da apropriação dos referenciais teórico-metodológico e ético-político que é realizada pelos profissionais, bem como das mediações necessárias à conexão entre o pensamento e a realidade na qual intervêm. Assim, os procedimentos escolhidos no desenvolvimento em ato da ação são decisivos no processo de materialização de determinada orientação teórica e ética. Nessa direção, afirma-se que, havendo uma intenção, deve haver necessariamente certo grau de planejamento da ação, no sentido de escolher os meios, projetar os resultados, antever as dificuldades de forma que se consigam aproximações sucessivas entre objetivos e finalidade proposta (ARGUMEDO, 2001).

Reconhece-se que no ato de seu desenvolvimento as ações socioeducativas veiculam a concepção de mundo e de homem que 


\section{tempordils}

LIMA, T. C. S. de; MIOTO, R. C. T. AÇÕES SOCIOEDUCATIVAS

- profissional possui, expressando sua vinculação com determinado projeto de sociedade e com determinada classe social. Desse modo, como toda ação humana consciente e, por isso, intencional, requer: um momento de planejamento ou de desenho da ação; de um momento de execução ou de intervenção na realidade; de um momento de avaliação ou de análise das modificações que se produziram na realidade (confronto com os objetivos propostos) (ARGUMEDO, 2001).

Portanto, considera-se relevante apreender como tem se estabelecido, no contexto do debate do Serviço Social, a relação entre pensamento e ação, tendo a ação socioeducativa como sua mediadora, entendendo o como fazer como ponto fundamental para garantir essa relação e consolidar a legitimidade do atual projeto profissional. Torna-se importante, então, apreender as influências que as tendências teóricas, mapeadas pela pesquisa, têm no debate das mediações necessárias à operacionalização da ação socioeducativa.

No escopo desse debate, a pesquisa realizada permitiu apreender o diálogo que envolve as principais referências teóricas presentes no Serviço Social e que aparecem no discurso profissional como base de sustentação da operacionalização das ações socioeducativas na perspectiva critico-dialética. Nas três ultimas décadas, o debate sobre essas ações no Serviço Social, sobretudo brasileiro, encontra sustentação nas contribuições de Antonio Gramsci, de Paulo Freire e, para alguns autores da área, também nas produções sobre o empowerment.

Antonio Gramsci é um autor importante no Serviço Social brasileiro, especialmente a partir da década de 1980. Os estudos baseados na sua obra revelam os esforços empreendidos para identificar mediações que estimulem a construção de processos 


\section{temporollis}

LIMA, T. C. S. de; MIOTO, R. C. T. AÇÕES SOCIOEDUCATIVAS

emancipatórios para a classe trabalhadora. A partir dos autores que foram pesquisados e que autorreferenciam seus estudos ao paradigma crítico-dialético, identificou-se o predomínio das bases gramscianas no debate das ações socioeducativas tanto no sentido de problematizar seu significado ontológico/epistemológico quanto no sentido de propor mediações para a sua operacionalização cuja localização circunda os conceitos de hegemonia e de intelectual (ABREU, 2002, 2004 ; ARGUMEDO, 2001; JESUS, 2005; PIRES, 2003; SIMIONATTO, 2004). Sob essas bases, a ação socioeducativa intenta simultaneamente o homem singular e o homem-massa, considerando que a possibilidade de um devir humano também está presente no âmbito individual (JESUS, 2005; LIMA, 2006; PIRES, 2003).

Paulo Freire é outro autor importante, cuja proposta considera que o ato de educar consiste em: uma relação que ocorre de maneira horizontal envolvendo sujeitos; um ato político, porque contém intencionalidade e direcionalidade ao reconhecer os conflitos e desigualdades entre os homens em sociedade; uma aprendizagem constante, porque acontece ao longo de toda a vida dos sujeitos e em todas as situações estabelecidas por eles; uma mudança que, ao ser portadora de um projeto social, intenciona ensinar algo que é desconhecido pelos sujeitos, contribuindo na construção de novas maneiras de viver (ARGUMEDO, 2001; BRANDÃO, 1985; FREIRE, 1983; PEREIRA, 2004).

Em Paulo Freire, o que define uma ação como educativa é a intenção de ensinar veiculada por ela, que irá conectar, através da ação, o educador ao projeto político e de sociedade da classe trabalhadora. Por isso, é considerada uma ação planejada e, para realizá-la, o educador necessita estabelecer objetivos informando o que e como pretende ensinar e explicitando neles os seus 


\section{temporalis}

LIMA, T. C. S. de; MIOTO, R. C. T. AÇÕES SOCIOEDUCATIVAS

princípios orientadores (teóricos e políticos) (ARGUMEDO, 2001; BRANDÃO, 1985; FREIRE, 1983; LIMA, 2006).

No Serviço Social brasileiro, essa proposta teve maior força no período do Movimento de Reconceituação, estendendo-se até meados da década de 1980. No entanto, verificou-se que ela não gerou na profissão análises aprofundadas acerca dos seus significados: conceitual e operativo. Mesmo existindo essas análises, sua repercussão nas obras dos Assistentes Sociais brasileiros não revela uma apropriação crítica das suas potencialidades e, na maioria das vezes, essas reflexões focam apenas na sua influência humanista, sem considerar seus viés marxiano e os avanços que realiza tendo por base as sociedades capitalistas periféricas.

$\mathrm{Na}$ atualidade, a concepção de empowerment aparece nos autores brasileiros como uma nova referência que pode contribuir na construção da ação socioeducativa na perspectiva do projeto éticopolítico. Faleiros (1999; 1997) é seu principal veiculador, afirmando que a proposta do empowerment busca: aumentar a defesa dos Direitos; implementar novos contratos em prol da ampliação da Cidadania; prestar informações de interesse do usuário acerca das políticas públicas; articular as pressões e as expressões do usuário; ampliar recursos administrativos e jurídicos para a defesa do usuário; integrar níveis de intervenção e formar redes de ação em favor do usuário; abrir canais de diálogo e participação etc. (FALEIROS, 1997; 1999). No entanto, a referência ao empowerment pelos autores do Serviço Social brasileiro revela uma incorporação mecânica do seu conceito porque aparece desvinculada do marco teórico no qual é gerada. De modo geral, as obras estudadas não apresentam análises profundas a respeito do significado conceitual e operativo implicados na proposta do empowerment. Apesar disso, não se pode invalidá-la ou credenciá-la à teoria do 
conhecimento calcada na pós-modernidade, simplesmente porque até o momento o Serviço Social não estabeleceu diálogo crítico suficiente de modo a incorporá-la ou a superá-la (LIMA, 2006).

Pautada nas três tendências, é possível assinalar que os objetivos propostos para a ação socioeducativa, como também os resultados ideais - que se pode ter como seu produto - estão relacionados e comprometidos com: a aproximação de certa finalidade, construída coerentemente a partir dos fundamentos que sustentam seus referenciais teórico-metodológico e ético-político. Para Argumedo (2001), esse conjunto de concepções é definido no contexto do imaginário social da sua época, permitindo definir e formular - respeitando seus fundamentos, sua matriz e diferentes ideias - distintas teorias e propostas de ação.

Assim, com base nas tendências mapeadas é possível afirmar que o Assistente Social trabalha a partir de uma concepção do que significa educar, supondo a adesão à determinada concepção de mundo como uma posição política. Esses são fatores determinantes e estruturantes da ação profissional, pois o sentido da ação muda segundo o entendimento que se tem a respeito do que é educar, por que educar, como educar, para quem e com qual finalidade.

\section{AS AÇÕES SOCIOEDUCATIVAS NO DEBATE DA DIMENSÃO TÉCNICO-OPERATIVA DO SERVIÇO SOCIAL}

A preocupação com a coerência no desenvolvimento das ações socioeducativas, de modo a conectar a finalidade ética da profissão - que reitera o compromisso com os interesses da classe trabalhadora e a transformação social - sem perder de vista o como fazer, que materializa essas intenções no plano concreto da realidade sócio-histórica, foi a pedra de toque para a efetivação de 


\section{tempordils}

LIMA, T. C. S. de; MIOTO, R. C. T. AÇÕES SOCIOEDUCATIVAS

algumas observações em relação à produção bibliográfica pesquisada.

Dentre tais observações destaca-se que a consolidação e a concretização do projeto ético-político é preocupação central da maior parte das obras pesquisadas, enfatizando como uma das exigências contemporâneas a necessidade de se ter competência técnico-operativa. Porém, o debate sobre tal dimensão aparece diluído nas obras, subentendendo-se que essa competência está diretamente relacionada à apropriação que o profissional realiza da dimensão teórico-metodológica e ético-política. De modo geral trazem indicativos para o debate da dimensão técnico-operativa e das ações socioeducativas, mas sua execução efetiva e as articulações no contexto de intervenção permanecem subentendidas. O como fazer fica pressuposto em afirmações genéricas como a: “[...] necessária apropriação crítica dos referenciais teórico-metodológico e ético-político [...]”; "[...] prática investigativa [...]”; “[...] compreensão da realidade [...]”; “ $[\ldots .$.$] avaliação das demandas [. .$.$] " etc.$

Os autores, que analisam mais detalhadamente as ações socioeducativas, evidenciam que há um trânsito necessário entre as demandas individuais e os espaços coletivos de discussão e de construção dessas demandas, sendo que esse trânsito é mediado/concretizado por ações de natureza educativa. Permanecem, no entanto, obscuras as mediações que constroem o processo de conexão entre o individual e o coletivo. Alguns desses autores sinalizam que há diferentes processos de intervenção, sobretudo quando problematizam os espaços de participação, em pontuar claramente suas diferenças. Consequentemente, não são apresentadas também as diferenças que envolvem a construção da participação social, ou a própria execução das ações socioeducativas no âmbito coletivo. 
As obras, que apresentam elementos caracterizadores das ações socioeducativas no âmbito da intervenção direta, ou seja, de demandas singulares, consideram o coletivo como parte constitutiva dessas ações porque as entendem como um processo que é iniciado com o repasse de informação/reflexão de demandas individuais, até seu reconhecimento e inscrição na esfera pública. A partir dessas obras, as ações socioeducativas engendram simultaneamente a intervenção no âmbito individual e no coletivo, uma vez que a participação política aparece associada à satisfação de necessidades imediatas e à conscientização dos usuários acerca das questões que os submetem ou os limitam individual e institucionalmente.

Por dedução, pode-se apreender que o processo de conscientização, de busca e de materialização de Direitos, de satisfação de necessidades humanas inicia-se com a informação, pois o ponto de partida reside no direito que o usuário tem às informações relacionadas às questões individuais, passando pelas questões que envolvem a instituição, os serviços que concretizam seus Direitos, até chegar às questões que perpassam a garantia, a ampliação, a reivindicação e inscrição na esfera pública de novos Direitos.

Pode-se perceber também, por parte dos autores, uma preocupação com a construção da responsabilidade técnica do Assistente Social no encaminhamento das demandas, mas não são explicitadas as dificuldades perpassadas no caminho percorrido pelo usuário até o acesso efetivo das políticas/serviços sociais. Ao mesmo tempo é possível constatar também um reconhecimento dos processos coletivos dos quais participam os profissionais, 0 que torna o resultado das ações "[...] uma questão em aberto, não programável e difícil de mensurar” (BERTANI, 1993, p. 45). 


\section{temporalis}

LIMA, T. C. S. de; MIOTO, R. C. T. AÇÕES SOCIOEDUCATIVAS

A partir dos autores é possível inferir que a ação socioeducativa, mesmo engendrando uma intenção política, por si só não garante que os resultados sejam correspondentes a sua intencionalidade. Isso porque a finalidade de construir novos pactos sociais em prol da transformação não está restrita a apenas uma categoria profissional.

Além disso, a totalidade das obras aborda a participação dos usuários junto aos segmentos organizados, mas sem detalhar como ela acontece e como pode ser estimulada e/ou garantida. Em algumas dessas obras, os grupos são apreendidos como sinônimo de espaços coletivos porque permitem o amplo repasse de informações/esclarecimentos/orientações de interesse do usuário. No entanto, merece ressalva que nem sempre a abordagem grupal desencadeia um processo reflexivo que permita a construção de uma identidade coletiva entre os sujeitos/usuários e de percepção política das suas demandas. Além disso, nem sempre as demandas conseguem ser percebidas e inseridas em um cenário mais amplo de discussão que vá além do problema imediato em discussão no grupo. Muitas vezes, as reflexões nos grupos acontecem isoladamente, tratando de questões específicas que envolvem a comunidade e/ou os indivíduos, sem aglutinar forças que permitam o reconhecimento e a inscrição das reivindicações individuais nas pautas dos movimentos sociais e/ou comunitários, nos Conselhos de Direitos e de políticas públicas etc.

Foi possível verificar também que na totalidade das obras pesquisadas existem diferentes denominações para as ações socioeducativas, sendo que essas diferenças muitas vezes dificultaram a apreensão dos significados conceituais apresentados pelos autores. Isso foi observado principalmente quando significações distintas eram credenciadas para explicar conceitos 


\section{temporalis}

LIMA, T. C. S. de; MIOTO, R. C. T. AÇÕES SOCIOEDUCATIVAS

com mesma denominação, ou então quando conceitos diferentemente denominados eram explicados pelos mesmos significados.

Finalmente, pelo mapeamento realizado, merece destaque a observação de que a proposta freireana e o empowerment apresentam indicativos procedimentais mais detalhados sobre a realização do processo educativo, aproximando-se mais da construção de uma base relacional de sustentação na operacionalização das ações socioeducativas. Isso coloca um diferencial em relação às contribuições gramscianas, que, apesar de suas múltiplas possibilidades de enraizamento no âmbito desse debate, não foram ainda suficientemente exploradas no contexto da intervenção profissional. As tendências - a freireana e o empowerment - revelam também que não há um rebatimento no Serviço Social dos estudos empreendidos por outras áreas do conhecimento e que, a partir do pensamento crítico-dialético, tem aprofundado esse debate.

Acredita-se que isso tende a inviabilizar um diálogo interdisciplinar consistente, sobretudo tratando-se da proposta de empowerment, que, no contexto das obras pesquisadas, revelou incorporações mecânicas de seu conceito ao aparecer desvinculada do marco teórico no qual é gerada. Os autores pesquisados que fizeram referência a essa proposta não apresentaram análises aprofundadas a respeito do significado conceitual e operativo nela implicado. Isso sinaliza para a necessidade de construção de um diálogo mais aprofundado acerca do empowerment de modo a incorporá-lo ou superá-lo criticamente.

As aproximações com o conjunto de produções sobre as ações socioeducativas, rapidamente apresentadas nesse artigo, incitaram ensaiar uma prospecção ou uma sistematização dos elementos que 


\section{tempordils}

LIMA, T. C. S. de; MIOTO, R. C. T. AÇÕES SOCIOEDUCATIVAS

podem caracterizar sua execução. Um ensaio no sentido de contribuir para o fortalecimento da reflexão sobre essas ações, considerando que é preciso explicitar sua dimensão técnicooperativa que, conjuntamente com as dimensões teóricometodológica e ético-política, compõe a totalidade necessária para a construção do exercício profissional. É nesse ensaio que consiste a próxima seção.

\section{SERVIÇO SOCIAL E AÇÕES SOCIOEDUCATIVAS: ENSAIO DE UMA CARACTERIZAÇÃO}

No paradigma crítico-dialético, considerar as ações socioeducativas como mediações necessárias às mudanças e/ou transformações não é completamente suficiente, uma vez que na trajetória histórica da profissão muitas foram as propostas cujo componente central consistia na mudança. Nessa perspectiva, existe uma diferença conceitual fundamental implícita na categoria educação, pois educar

[...] significa incitar a criação ou fortalecer determinados aspectos da individualidade e da coletividade [...] [,] volta-se para a formação de um tipo de homem que [...] intenta a mudança sem a referência a um "padrão pré-fixado" e justificado a partir da "crença em uma natureza humana ideal" (PIRES, 2003, p. 288-290).

O aspecto revolucionário em tomar como base o paradigma críticodialético para o exercício profissional consiste em não estabelecer um padrão/modelo operacional para o desenvolvimento das ações que o materializam. Contudo, é importante que os princípios norteadores da profissão estejam claramente conectados a uma forma de proceder, condensando e expressando de maneira coerente os valores neles veiculados porque a perspectiva 


\section{temporolis}

LIMA, T. C. S. de; MIOTO, R. C. T. AÇÕES SOCIOEDUCATIVAS

dialética envolve simultânea e organicamente uma opção teórica e política, como também orientações operacionais relativas a procedimentos e instrumentos.

Nessa perspectiva, as ações socioeducativas devem exprimir o vínculo de adesão e articulação com as ideias, os objetivos e as propostas que envolvem o projeto político da classe trabalhadora. O movimento da sua operacionalização articula dialeticamente as três dimensões referidas ao Serviço Social (teórica, ética e técnica) e se materializa através: do conhecimento/investigação da realidade sócio-comunitária-institucional na qual se intervém; do planejamento e da documentação do processo de trabalho; das formas escolhidas de abordagens dos sujeitos para quem se destina a ação; da definição dos instrumentos técnico-operativos e outros recursos implicados na execução da ação.

Tal movimento incide tanto na relação estabelecida entre Assistente Social e usuário/grupos de usuários, quanto na relação individual-coletivo. Nele o marco teórico sempre é acionado a partir de determinada situação real/concreta e de dado espaço sócio-ocupacional que envolve os sujeitos (profissionais/equipes e usuários) implicados na ação. Esse entendimento condiciona os objetivos das ações que, por sua vez, serão responsáveis por imprimir-lhes determinadas características, influenciando as formas de operacionalizá-la.

Conforme o apreendido nas obras pesquisadas, as ações socioeducativas perpassam diferentes processos de intervenção e apresentam características diferentes quando vinculadas a cada um deles porque tratam de demandas e objetivos diferentes, apesar de compartilharem a mesma finalidade. Assim, tomando como base a caracterização de Mioto e Lima (2009), é possível referenciá-las a dois processos interventivos, especialmente: o 


\title{
tempordlis
}

LIMA, T. C. S. de; MIOTO, R. C. T. AÇÕES SOCIOEDUCATIVAS

Processo Político-organizativo e o Processo Socioassistencial ${ }^{5}$. De acordo com as autoras, os Processos Político-organizativos

\begin{abstract}
[...] privilegiam e incrementam discussões e encaminhamentos na esfera pública. Seu foco consiste em dinamizar e instrumentalizar a participação, sempre respeitando o potencial político e o tempo dos sujeitos envolvidos. As ações consideram as necessidades imediatas, mas projetam a médio e a longo prazos a construção de novos padrões de sociabilidade entre os sujeitos porque estão guiadas pela premissa da democratização dos espaços coletivos e pela criação de condições para a disputa com outros projetos societários. A universalização, a ampliação e a efetivação do acesso aos Direitos são pautas nos mais diferentes espaços de Controle Social onde são questionadas as relações estabelecidas no espaço sócio-ocupacional, na comunidade e nas diferentes instituições (MIOTO; LIMA, 2009, p. 41).
\end{abstract}

Nesses Processos, as ações socioeducativas apresentam especificidades, principalmente nos objetivos ${ }^{6}$, porque intentam o diálogo problematizador e a coletivização de demandas individuais. Seus principais objetivos são: a mobilização, a organização e a participação social. Nesse âmbito, a assessoria pode ser um

${ }^{5}$ Cabe lembrar que a caracterização das ações socioeducativas nesses dois Processos tem o intuito de contribuir para uma apreensão mais didática sobre o processo de trabalho, não significa compartimentalizar essas ações, negando sua transversalidade e seu movimento dialético no ato da sua realização.

${ }^{6}$ Os objetivos não devem ser confundidos com as finalidades, estas se referem mais às diretrizes políticas gerais, à filosofia de ação. Para Mioto e Nogueira (2006), as finalidades apresentam as seguintes características: são abstratas, ideais, de longo alcance e estão mais ligadas a valores, não permitindo avaliação direta; enquanto os objetivos são concretos, reais, de alcance em tempo determinado e estão ligados ao mundo dos bens e serviços, permitindo avaliação direta. 
recurso importante para contribuir na articulação dos diferentes segmentos de usuários de modo a organizar e apresentar suas reivindicações na esfera pública como sujeito político. Conforme destaca Lima et al. (2011, p. 7),

[...] as ações destinadas ao atendimento de demandas coletivas implicam em considerar os problemas sociais que envolvem a comunidade atendida. Nesse processo, as informações transmitidas, os estudos realizados, o conhecimento profissional acumulado, o saber popular e o vínculo profissional-usuário devem ser colocados a serviço do bem comum, ou seja, na organização de demandas e necessidades coletivas que envolvem sujeitos concretos que devem participar ativamente na esfera pública, reivindicando e decidindo sobre as formas de concretização dos direitos sociais (LIMA et al., 2011, p. 7).

\section{Os Processos Socioassistenciais}

[...] correspondem ao conjunto de ações desenvolvidas no âmbito da intervenção direta com os usuários nos diferentes campos de intervenção a partir de demandas singulares. Sua lógica reside em atender o usuário como sujeito, visando responder as demandas/necessidades particulares e singulares numa perspectiva de construção de sua autonomia no âmbito das relações institucionais e sociais ao remetê-lo para a participação política em diferentes espaços, dentre os quais se incluem: as próprias instituições, programas, serviços e também os conselhos de direitos, os movimentos de base sóciocomunitária e os movimentos sociais na sua diversidade (MIOTO; LIMA, 2009, p. 42). 


\title{
tempordils
}

LIMA, T. C. S. de; MIOTO, R. C. T. AÇÕES SOCIOEDUCATIVAS

Aqui as ações socioeducativas estão estruturadas sobre dois pilares: a socialização de informações e o processo reflexivo, que sustentam o processo educativo cuja finalidade está condicionada aos princípios ético-politicos da profissão (MIOTO, 2010). O processo educativo pode ser entendido como toda a experiência na qual as pessoas mudam a sua maneira de compreender o mundo e as relações humanas. Através dele enriquecem sua maneira de encarar a si mesmas, os outros e a realidade, ao mesmo tempo em que envolve a conquista de novas forças e novos instrumentos para transformar a realidade vivenciada.

Através da pesquisa, os indicativos encontrados sobre os objetivos das ações socioeducativas permitem considerá-las como um processo dinâmico que remete a uma luta coletiva, de organização política, mas que também acontece no âmbito individual através da apropriação da informação e dos caminhos de acesso a políticas e serviços sociais, implicando no reconhecimento das necessidades individuais como coletivas.

De acordo com Pires (2003, p. 317), o

\begin{abstract}
[...] singular precisa desenvolver toda uma série de conhecimentos que, embora individuais, não são de caráter 'individualista'. É um conhecimento [...] social não só porque sua edificação só é possível socialmente [...] [,] mas porque leva em conta compulsoriamente o coletivo.
\end{abstract}

Reconhecer como fundamental a ação socioeducativa no âmbito individual dos Processos Socioassistenciais significa dar visibilidade à necessidade de se trabalhar o sujeito em sua singularidade, suas habilidades, capacidades, potencialidades e limites. Mas esse reconhecimento não se constitui no final do processo, pelo contrário, “[...] ele é um meio porque o horizonte não é o 


\section{temporalis}

LIMA, T. C. S. de; MIOTO, R. C. T. AÇÕES SOCIOEDUCATIVAS

melhoramento ético individual, mas a transformação social" (PIRES, 2003, p. 319).

Nesse sentido, a relação entre a ação socioeducativa, a conscientização e a participação social é evidenciada como requisito para que os sujeitos alcancem graus sempre ascendentes de autonomia. Autonomia na perspectiva da possibilidade de livre decisão e da afirmação da vontade dos indivíduos e da coletividade no plano real ( NETTO, 1996).

Assim, as ações socioeducativas tendem a oportunizar ao usuário uma compreensão ampla e concreta: da sociedade em que vive, dos direitos que possui nessa sociedade, da possibilidade de coletivização de suas necessidades de modo a ampliar seus direitos na esfera pública. Nesse movimento está pressuposta a responsabilização ética que o profissional em ato deve ter e que é expressa: nas dimensões assistenciais do trabalho, na relação de acolhimento, de criação de vínculo, de produção de resolutividade e de estímulo à construção de graus crescentes de autonomia no modo de o usuário se relacionar com a família, com a comunidade e com o mundo (LIMA, 2004).

Enfim, o percurso de trabalho que envolve a ação socioeducativa pressupõe a definição de matriz teórico-metodológica, de finalidade, de conhecimento da realidade e dos sujeitos para quem é destinada a intervenção, de objetivos, para, então, proceder à escolha de abordagens, instrumentos e recursos que viabilizem a consecução da ação projetada.

\section{CONSIDERAÇÕES FINAIS}

Apresentar o debate sobre as ações socioeducativas implica considerar o diálogo construído pela categoria profissional sobre 


\section{tempordils}

LIMA, T. C. S. de; MIOTO, R. C. T. AÇÕES SOCIOEDUCATIVAS

essas questões. Condensou-se aqui parte dos estudos empreendidos sobre o tema, destacando que as ações profissionais sempre estão conectadas a determinados conhecimentos e valores que orientam o processo de sua materialização ao referenciá-las a determinados sujeitos, a determinada realidade, a determinado projeto societário e a um momento histórico. Salienta-se que a escolha de um paradigma teórico para um projeto profissional está ligada ao reconhecimento, em dado período, da sua validade argumentativa. Está, no âmbito das ideias, confrontada tanto por outros paradigmas como pela sua capacidade de se concretizar como respostas às questões colocadas pela realidade social.

Ter clareza dessa realidade permite aos Assistentes Sociais refletirem sobre o conteúdo volitivo contido nas suas ações, considerando que eles, por si próprios, não garantem a transformação social apontada pelo projeto profissional. Por isso, reconhecer as múltiplas determinações que limitam o alcance da finalidade das ações profissionais remete a entender o desenrolar dessas ações no campo das tensões que se colocam na atualidade entre projetos em confronto. Esse campo de tensões é que, contraditoriamente, cria possibilidades de transformação social porque as relações sociais são entendidas como construções humanas, que, como produtos históricos, são passíveis de mudança/superação.

A aproximação com as referências gramsciana, freireana e do empowerment como balizadoras do debate sobre a consecução das ações socioeducativas permite o desvelamento de possíveis caminhos para a construção de uma ação responsável. Tanto em relação aos significados das categorias-chave que as dotam de conteúdo, como de coerência quanto ao compromisso histórico presente no projeto profissional do Serviço Social. 
Ainda que pese a incompletude desta iniciativa, espera-se que seu ponto de chegada contribua para outras partidas em torno de novas reflexões e estudos sobre a sistematização da intervenção profissional/ações socioeducativas - sua sistematização entendida como forma de conectar dialética e coerentemente a dimensão técnico-operativa com as dimensões ético-política e teóricometodológica. Nessa perspectiva busca-se qualificar o processo interventivo do assistente social visando à materialização do projeto ético-político, bem como a consolidação de sua hegemonia no horizonte da defesa, ampliação e efetivação do acesso aos Direitos, sem abrir mão da transformação social e da emancipação humana como totalidade.

\section{REFERÊNCIAS}

ABREU, M. M. A dimensão pedagógica do Serviço Social: bases histórico-conceituais e expressões particulares na sociedade brasileira. Revista Serviço Social e Sociedade, São Paulo, n. 61, p. 43-71, 2004.

. Serviço Social e a organização da cultura: perfis pedagógicos da prática profissional. São Paulo: Cortez, 2002.

ARGUMEDO, M. A. El trabajador social como educador. 2001. $264 \mathrm{f}$. Tese (Doutorado em Serviço Social) - Faculdade de Serviço Social, Pontifícia Universidade Católica, São Paulo, 2001.

BERTANI, I. F. O processo de trabalho do Serviço Social no ambulatório do InCor. Revista Serviço Social e Sociedade, São Paulo, n. 42, p. 41-52, ago. 1993.

BRANDÃO, C. R. A educação como cultura. São Paulo: Brasiliense, 1985. (Coleção Primeiros Passos). 


\section{tempordils}

LIMA, T. C. S. de; MIOTO, R. C. T. AÇÕES SOCIOEDUCATIVAS

CARVALHO, A. M. P. de. A questão da transformação e o trabalho social: uma análise gramsciana. São Paulo: Cortez, 1983

FALEIROS, V. de P. Desafios do Serviço Social na era da globalização. Revista Serviço Social e Sociedade, São Paulo, n. 61, p. 152-186, nov. 1999.

. Estratégias em Serviço Social. São Paulo: Cortez, 1997.

FREIRE, P. Educação e mudança. 4. ed. Trad. Moacir Gadotti e Lílian L. Martin. Rio de Janeiro: Paz e Terra, 1983.

IAMAMOTO, M. V. O Serviço Social na contemporaneidade: trabalho e formação profissional. 2. ed. São Paulo: Cortez, 1999.

JESUS, C. da S. de. O Serviço Social e as ações sócio-educativas com famílias: um estudo sobre as publicações dos assistentes sociais. 2005. 164 f. Dissertação (Mestrado em Serviço Social) Programa de Pós-Graduação em Serviço Social, Universidade Federal de Santa Catarina, Florianópolis, 2005.

LIMA, K. M. C. de et al. O Serviço Social no PET Saúde da Família: a experiência na UBS Graciliano Ramos/Maceió-AL. Maceió: Edufal, 2011. [no prelo].

LIMA, T. C. S. de. As ações sócio-educativas e o projeto éticopolítico do Serviço Social: tendências na produção bibliográfica. 2006. 172 f. Dissertação (Mestrado em Serviço Social) - Programa de Pós-Graduação em Serviço Social, Universidade Federal de Santa Catarina, Florianópolis, 2006.

. A intervenção profissional do Serviço Social no contexto da Cidadania e dos Direitos: pensando as ações sócio-educativas. 


\section{temporalis}

LIMA, T. C. S. de; MIOTO, R. C. T. AÇÕES SOCIOEDUCATIVAS

2004. 82 f. Trabalho de Conclusão de Curso (Graduação em Serviço Social) - Departamento de Serviço Social, Universidade Federal de Santa Catarina, Florianópolis, 2004.

LIMA, T. C. S.; MIOTO, R. C. T. Procedimentos metodológicos na construção do conhecimento científico: a pesquisa bibliográfica. Revista Katalysis, Florianópolis, v. 10, n. esp., p. 37-45, 2007.

MERCADO-MARTÌNEZ, F. J. O processo de análise qualitativa dos dados na investigação sobre serviços de saúde. In: BOSI, M. L. M.; MERCADO-MARTìnEZ, F. J. Pesquisa qualitativa de serviços de saúde. Petrópolis: Vozes, 2004. p. 137-174.

MIOTO, R. C. T. Orientação e acompanhamento de indivíduos, grupos e famílias. Cadernos Capacitação em Serviço Social: direitos sociais e competências profissionais, Brasília, módulo 5, p. 1-16, 2010.

MIOTO, R. C. T.; LIMA, T. C. S. de. A dimensão técnico-operativa do Serviço Social em foco: sistematização de um processo investigativo. Revista Textos \& Contextos, Porto Alegre, v. 8, n. 1, p. 22-48, jan./jun. 2009. Disponível em: <http://www.pucrs.br/textos>.

MIOTO, R. C. T.; NOGUEIRA, V. M. R. Sistematização, planejamento e avaliação das ações dos assistentes sociais no campo da saúde. In: MOTA, A. E. et al. (Orgs.). Serviço Social e saúde: formação e trabalho profissional. São Paulo: Opas/OMS/MS/ Cortez, 2006. p. 273-303.

NETTO, J. P. La construcción del proyecto ético-político del Servicio Social frente a la crisis contemporánea. In BORGIANNI, E.; GUERRA, Y.; MONTAÑO, C. (Orgs.). Servicio Social critico: hacia la construcción del nuovo proyeto ético-político profesional. São Paulo: Cortez/ Biblioteca Latinoamericana de Servicio Social, 2005. p.271-296. 


\section{temporalis}

LIMA, T. C. S. de; MIOTO, R. C. T. AÇÕES SOCIOEDUCATIVAS

- Transformações societárias e Serviço Social: notas para uma análise prospectiva da profissão no Brasil. Revista Serviço Social e Sociedade, São Paulo, ano 17, n. 50, p. 87-132, abr. 1996.

PEREIRA, L. P. L. S. Programa Saúde da Família: estratégia de saúde - espaço de práticas educativas transformadoras para o século XXI. Revista Ser Social, Brasília, v. 1, n. 1, p. 77-120, jan./jun. 2004.

PIRES, S. R. de A. Serviço Social: função educativa e abordagem individual. 2003. 236 f. Tese (Doutorado em Serviço Social) - Faculdade de Serviço Social, Pontifícia Universidade Católica, São Paulo, 2003.

SIMIONATTO, I. As expressões ideoculturais da crise capitalista da atualidade. Cadernos de Capacitação em Serviço Social e Política Social: módulo 01. Brasília, 1999. p. 77-90.

. Gramsci, sua teoria: influência no Brasil, incidência no Serviço Social. 3.ed. São Paulo-Florianópolis: Cortez/UFSC, 2004.

SPINA, M. B.; FERREIRA, M. Una mirada inicial al quehacer educativo las organizaciones publicas no estatales. El aporte pedagógico de los profesionales de las OPNEs prestadoras de servicios sociales. Boletín Electrónico Surá, Argentina, n. 92, mar. 2004. Disponível em: <http://www.ts.ucr.ac.cr/suradoc.htm>.

YAZBEK, M. C. Os fundamentos do Serviço Social na contemporaneidade. Cadernos de Capacitação em Serviço Social e Política Social: módulo 04. Brasília, 2000. p. 19-34.

YAZBEK, M. C. Classes subalternas e assistência social. São Paulo: Cortez, 1999. 
